\title{
Rectal Fecaloma: Successful Treatment Using Endoscopic Removal
}

\author{
Eiji Sakai $^{\mathrm{a}}$ Yasuhiro Inokuchi ${ }^{\mathrm{a}}$ Masahiko Inamori ${ }^{\mathrm{b}}$ Takashi Uchiyama $^{\mathrm{b}}$ Hiroshi lida $^{\mathrm{b}}$

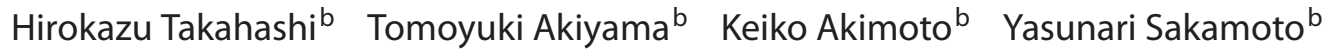 \\ Koji Fujitab Masato Yoneda ${ }^{b}$ Yasunobu Abe ${ }^{b}$ Noritoshi Kobayashi ${ }^{b}$ Kensuke Kubota ${ }^{b}$ \\ Satoru Saito $^{b}$ Atsushi Nakajimab \\ Gastroenterology Divisions, ${ }^{a}$ Yokohama Sakae Kyosai Hospital and ${ }^{b}$ Yokohama City University School of Medicine, \\ Yokohama, Japan
}

Dear Sir,

A 78-year-old woman, who had been monitored because of diabetes mellitus for several decades, complained of constipation for 1 week. An abdominal X-ray examination showed that feces had filled the descending and sigmoid colon. An abdominal computed tomography examination showed an impacted fecal ball with calcification, $5 \mathrm{~cm}$ in size, in her rectum. We diagnosed her as having a fecaloma in her rectum. A colonoscopy revealed the rectal fecaloma to be black, smooth and ball-like in appearance (fig. 1). The fecaloma was successfully removed endoscopically.
Fecalomas are hard, laminated masses that sometimes contain calcification and are usually located in the sigmoid colon or rectum. Complications of fecalomas include constipation, ulceration, bleeding and perforation of the colon. Treatments include laxatives, enemas, rectal evacuation, surgical colotomy (which is required in patients with short-segment Hirschsprung disease), and endoscopic removal - as in the present patient. Impaired anorectal function arising from diabetic neuropathy may have caused the fecaloma in present patient.

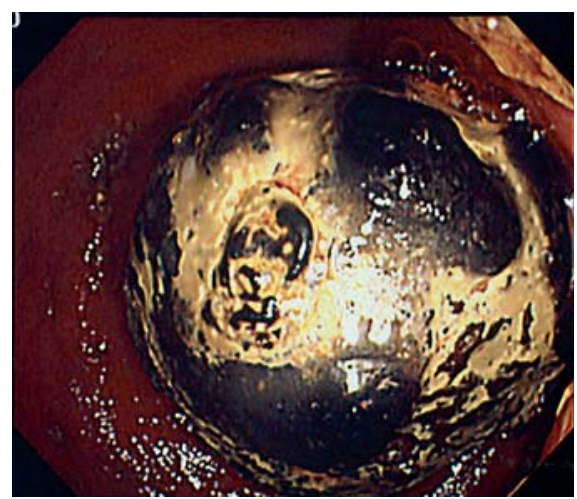

Fig. 1. A colonoscopy shows a rectal fecaloma with a black, smooth and ball-like appearance.

\section{KARGER \\ Fax +41 613061234 \\ E-Mail karger@karger.ch}

www.karger.com (c) 2007 S. Karger AG, Basel 0012-2823/07/0754-0198\$23.50/0

Accessible online at: www.karger.com/dig
Masahiko Inamori

Yokohama City University, Gastroenterology Division

3-9, Fukuura, Kanazawa-ku

Yokohama, Kanagawa 236-0004 (Japan)

Tel. +81 45787 2640, Fax +81 45784 3546, E-Mail inamorim@med.yokohama-cu.ac.jp 